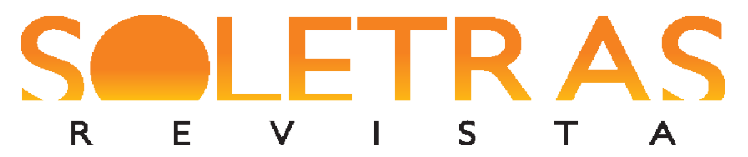

N. 33 ï 2017.1 ï LETICIA SICURO CORRÊA

\title{
Entrevista
}

\section{Laboratório de Psicolinguística e Aquisição da Linguagem (LAPAL)}

\author{
Letícia Sicuro Corrêa $^{1}$
}

Pontifícia Universidade Católica do Rio de Janeiro

\section{Entrevista concedida aos professores Kátia Abreu e Eduardo Kenedy}

Soletras: Quando o seu LAB foi fundado? Qual foi sua experiência em LABs de Psicolinguística anterior à fundação do LAB que coordena?

O LAPAL (Laboratório de Psicolinguística e Aquisição da Linguagem ï PUC-Rio) passou a assumir esse nome em 2000, em consequência da obtenção de espaço físico, da parte da PUC, e de recursos da FAPERJ, para dar continuidade e ampliar as atividades que vinham sendo conduzidas no então chamado Laboratório de Psicolinguística, que existia em espaço improvisado desde 1995.

Durante o doutorado, tive contato com o trabalho experimental conduzido na então unidade de Psicologia do Desenvolvimento do Medical Reseach Council, em Londres, que reunia pesquisadores e doutorandos de diferentes instituições vinculadas à Universidade de Londres, em seminários voltados para aquisição da linguagem, coordenados por Richard Cromer. Em 1997, fiz uma visita curta ao Laboratoire de Psychologie Experimentel da Université Libre de Bruxelles, aproveitando a ida a um congresso, tendo sido recebida por José Morais e Réjane Kolinsky e posta em contato com José Alegria, pois, na época, estava com interesse em processamento da língua escrita. Em 2005 e em 2008, fui pesquisadora visitante no então Laboratoire de Psychologie Experimentel, Université Paris V, em contato com Celia Jakubowicz, com quem compartilhava interesse em uma integração entre a pesquisa em processamento, aquisição da linguagem e DEL (Déficit ou Distúrbio Específico da Linguagem), sob ótima minimalista. Nesse laboratório, pude também observar o trabalho experimental de Juan Seguí, voltado para o processamento da linguagem por adultos. A

1 Coordenadora do Laboratório de Psicolinguística e Aquisição da Linguagem (LAPAL). Docente da PUC-Rio, onde atua na Graduação em Letras e na Pós-Graduação Estudos da Linguagem, na área de Psicolinguística. Pesquisador 1B CNPq, Cientista do Nosso Estado da FAPERJ. 1scorrea@puc-rio.br 


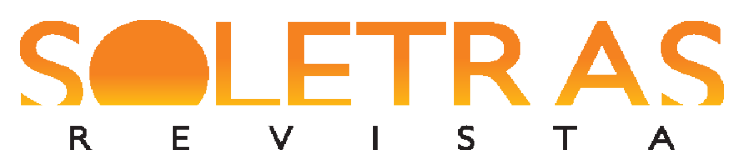

N. 33 ï 2017.1 ï LETICIA SICURO CORR̂̂A

montagem do LAPAL teve, não obstante, a orientação de Emmanuel Dupoux, convidado a atuar no I Instituto de Inverno em Língua e Cognição, ocorrido em 1999 na PUC-Rio, o qual recebeu, em doutorado-sanduíche no Laboratoire de Sciences Cognitives et Psycholinguistique, de Paris, minha então orientanda de doutorado, Cristina Name, que lá aprendeu a técnica da escuta preferencial que viríamos a implantar no baby lab do LAPAL. A vinda de Roberta Golinkoff, da University of Delaware, como convidada do II Instituto de Inverno em Língua e Cognição em 2001 também contribuiu para a montagem do baby lab, que veio a ser o primeiro no Brasil e talvez na América Latina.

Soletras: Quais os principais temas de pesquisa que seu LAB vem contemplando ao longo dos anos?

Ainda na primeira fase, bem precária, do Laboratório de Psicolinguística, trabalhamos com o processamento da referência pronominal por crianças e adultos, buscando restrições ao uso e interpretação dessas formas, para além das restrições gramaticais, ou seja, considerando a possibilidade de acesso diferenciado a possíveis antecedentes das formas pronominais entre sentenças, em função de fatores pertinentes à sua posição da estrutura em que foram introduzidos, sua relação com o tópico do discurso, animacidade, dentre outros, que podem determinar o grau de acessibilidade dessas formas. Passei, então, a verificar a permanência da informação de ordem gramatical (como relativa a traços de gênero ou número) na memória de trabalho, após o fechamento de uma unidade de sintática. Nessa direção, demos início ao estudo de erros de atração na produção da fala, tal como evidenciados na concordância de número entre sujeito e verbo, como forma explorar a acessibilidade relativa de informação gramatical pertinente a constituintes internos ao sujeito, passíveis de intervir na forma como o verbo se apresenta. Trabalhamos também com nomes animados cujo gênero gramatical poderia não coincidir com o sexo do referente do sintagma referencial/pronome (ex. a vítima, a testemunha, que podem se referir a indivíduos do sexo masculino) em diferentes ambientes sintáticos. A pergunta era em que condições o gênero gramatical do antecedente (e não o gênero natural de seu referente) seria recuperado, sob o pressuposto de que o fechamento de uma unidade sintática promove o esvaecimento da informação gramatical em prol da permanência da informação de ordem semântica relativa ao referente da expressão em questão. O interesse por questões envolvendo gênero gramatical motivou a retomada de questões pertinentes à identificação da gramática da língua na aquisição da linguagem. Diante 


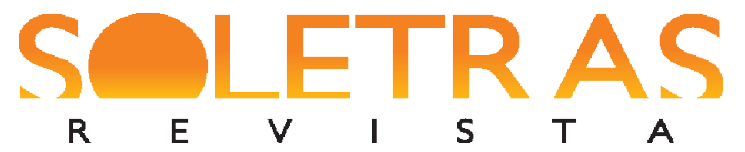

N. 33 Ï 2017.1 ï LETICIA SICURO CORRÊA

da arbitrariedade da atribuição de nomes a classes de gênero em uma dada língua, seria esperado um processo de aquisição relativamente tardio por supostamente depender de frequência e inferência. Contudo, observa-se o contrário. Os erros são poucos e só tendem a aparecer depois que a identificação do gênero já transcorre sem dificuldades. Buscamos então explorar a sintaxe em andamento em fase bem inicial do processo de aquisição como instrumental à identificação do gênero de nomes via concordância. Isso nos levou à busca pela sensibilidade precoce a elementos funcionais no fluxo da fala e a variações em sua forma. Tivemos então um ciclo de estudos voltados para identificação de gênero, número, pessoa, aspecto e modo na gramática do português do Brasil, via experimentos de compreensão e produção induzida, no qual também se inclui a aquisição de complementos acusativos clíticos e com pronome forte, e distinções de número e gênero nessas formas, em estudo contrastivo com o espanhol. Retomando a recursividade, que havia sido foco de minha de tese em processamento e aquisição de relativas, voltamos a explorar custo de processamento, estratégias de minimização de custo, considerando as relativas cortadoras e a presença de pronome resumptivo, na produção e na compreensão de crianças e adultos, assim como a possibilidade de minimização de custo em função do mapeamento do sujeito de relativas restritivas de objeto a um referente, levando em conta a incrementalidade do processamento. Questões vinculadas a custo de processamento e à autonomia do processador sintático foram então enfocadas à luz do modelo de computação on-line que vimos desenvolvendo, tomando por base pressupostos minimalistas (em parceria com Maria Augusto, da UERJ). A recursividade na língua como possivelmente instrumental ao desenvolvimento de habilidades cognitivas superiores, em contrapartida ao custo de processamento, foi então explorada em função de projeto que agregou duas teses ï uma voltada para a cognição numérica e outra para teoria da mente. Atualmente, vimos explorando questões pertinentes a localidade e acessibilidade com vistas a integrar duas fases da pesquisa que vimos conduzindo, retomando então aspectos do processamento/aquisição de formas pronominais, acrescidas de estruturas elípticas. De forma integrada à pesquisa em processamento linguístico pelo adulto e aquisição pela criança, temos como tema ou foco de interesse, de teor mais aplicado, o estudo de manifestações do DEL (Déficit ou Distúrbio Específico da Linguagem) em crianças em idade escolar, considerando possíveis compartilhamentos de sintomas e/ou recursos com outras síndromes também de incidência relativamente alta (como TDAH, TEA e Dislexia). 


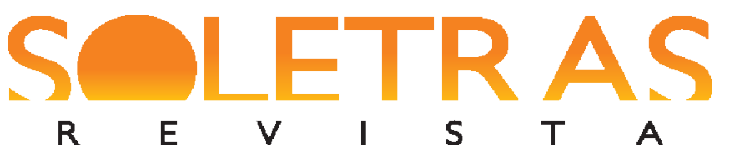

N. 33 ï 2017.1 ï LETICIA SICURO CORRÊA

Diferenças entre manifestações do DEL e síndrome de Williams foram anteriormente exploradas.

Além das linhas de pesquisa em processamento e aquisição da linguagem e em problemas da/na linguagem, por mim conduzidas, no Grupo de pesquisa do LAPAL, esse grupo de pesquisa incorpora ainda uma linha de investigação em leitura e escrita e outra em sintaxe experimental, conduzidas pelas professoras Erica Rodrigues e Cilene Rodrigues, respectivamente.

Soletras: Quais as principais técnicas experimentais que vêm sendo empregadas nas pesquisas de seu Lab nos últimos anos?

No processamento conduzido por adultos e adolescentes, vimos utilizando leitura automonitorada e rastreamento ocular, assim como produção induzida por preâmbulo. No estudo da aquisição da linguagem em fase inicial, utilizamos a técnica da escuta ou atenção preferencial, adequada a crianças com idade inferior a dois anos e fixação preferencial do olhar, ambas dependentes do babylab. Em experimentos conduzidos em escolas, assim como na avaliação de habilidades linguísticas de crianças, fazemos uso de identificação de imagens a partir de sentenças, manipulação de brinquedos, em tarefas de compreensão, e produção induzida via repetição, reconto ou complementação de frases (estilo cloze, conduzido oralmente).

Soletras: Você poderia fazer uma estimativa do total de pesquisas de mestrado e doutorado que foram conduzidas no Lab?

A partir de 2000, quando temos o LAPAL montado (com cabine para adultos e baby lab, e equipamento de rastreamento ocular) e assim nomeado, temos 33 dissertações de mestrado e 16 teses de doutorado concluídas, sob minha orientação e dos docentes do Programa de Pós-Graduação Estudos da Linguagem da PUC-Rio vinculados ao LAPAL ï Erica Rodrigues (desde 2008) e Cilene Rodrigues (desde 2012).

Soletras: O Lab integra alguma rede de cooperação? Poderia citar outros Labs parceiros? 


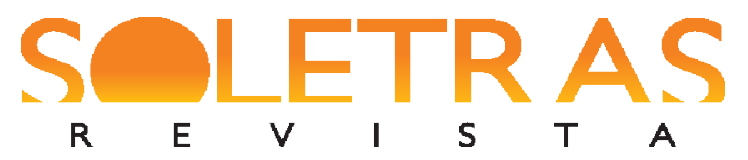

N. 33 ï 2017.1 ï LETICIA SICURO CORRÊA

Mantemos cooperação com o Círculo de Linguística da Universidade Nova de Lisboa, e com o Instituto Politécnico de Setúbal, que oferece curso de formação de terapeutas da linguagem. Prestamos assessoria a estes, assim como a um grupo da Universidade del Litoral em Santa Fé, Argentina. Recentemente, fizemos contato de parceria com o Multilingualism \& Language Development Lab, da School of Psychology and Clinical Language Sciences, University of Reading.

No Brasil, o NEALP ï Núcleo de Estudos em Aquisição da Linguagem e Psicolinguística da UFJF tem colaborado com a cessão de espaço para teste de bebês residentes em JF e compartilha interesses com o LAPAL, uma vez que fundado e conduzido por ex-orientandos. O LAPROL (Laboratório de Processamento Linguístico) da UFPB, também com ex-orientando, nos tem convidado a integrar projetos. Mais recentemente, desenvolvemos um projeto em colaboração com a UFC, onde se vem explorando o uso de rastreamento ocular. Entretanto, a despeito de interesses e pressupostos comuns, observa-se que os Labs se desenvolvem de forma consideravelmente autônoma, adquirindo identidade própria, o que é algo positivo.

Como integrantes do Grupo de Pesquisa do LAPAL, temos pesquisadores do programa de Linguística da UERJ ï Marina Augusto e Renê Forster, antes vinculados ao LAPAL em doutorado ou pós-doc/recém-doutor. A primeira desenvolve projeto de extensão sobre o DEL, integrado aos projetos sobre o DEL do LAPAL.

Soletras: Além de trabalhos teóricos de interesse para a área da Psicolinguística, seu Lab desenvolve também pesquisas de interface com a área da Saúde elou da Educação? Se sim, quais?

Sim, como mencionei acima, temos uma linha voltada para transtornos da/na linguagem, centrada em manifestações atribuíveis ao DEL, passíveis de serem compartilhadas com outras síndromes, e buscamos identificar o que seria, no português do Brasil, o/um marcador do DEL. Nessa linha de investigação, conduzida com crianças de escolas públicas das redes municipal e estadual do Rio de Janeiro, desenvolvemos um instrumento de avaliação de habilidades linguísticas de crianças (MABILIN ï Módulos de Avaliação de Habilidades Linguísticas), nos domínios da sintaxe, morfossintaxe e interface gramáticapragmática, assim com testamos um procedimento de intervenção que pode contribuir para a aquisição tardia ou para a otimização do desempenho no processamento de estruturas de alto 


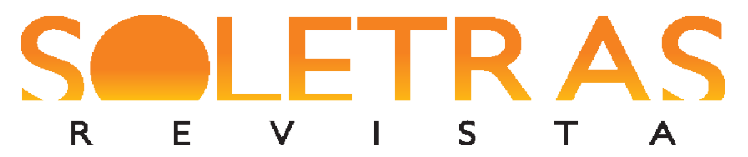

N. 33 ï 2017.1 ï LETICIA SICURO CORRÊA

custo, particularmente afetadas no DEL, como também de difícil condução no quadro do TDAH, por exemplo. O LAPAL tem recebido como pós-graduandos e colaboradores profissionais da fonoaudiologia. Atualmente, mantemos colaboração com a Fonoaudiologia da UFF e com o Departamento de Psicologia da PUC-Rio. Todo o trabalho de teor aplicado tem tido apoio da FAPERJ, via Editais Cientistas do Nosso Estado. Em função da colaboração com a Universidade Nova de Lisboa e o Instituto Politécnico de Setúbal, estaremos em breve disponibilizando uma plataforma que dará acesso ao MABILIN para profissionais de saúde e educação, no Brasil e em Portugal.

Soletras: Deixe uma palavra de seu Lab para os leitores alunos de graduação interessados em ingressar na área da psicolinguística experimental.

O estudo do processamento e da aquisição da linguagem típica e atípica se abre a diferentes caminhos de investigação, ainda pouco explorados. No Brasil, trata-se de um campo ainda pouco desenvolvido. Logo, está apto a receber jovens curiosos, dinâmicos e também reflexivos. Requer interesses diversificados na busca por uma linguagem que possibilite o desenvolvimento de pesquisa interdisciplinar. Requer dedicação, persistência (com certo perfeccionismo, pois o trabalho experimental o requer) e prazer na interação com aqueles que contribuem voluntariamente com dados para a pesquisa, particularmente as crianças. O trabalho em equipe é fundamental, permitindo que se compartilhem dúvidas e alegrias. Como todo trabalho de pesquisa, este requer razão e paixão. Enfim, a psicolinguística experimental é um dos campos de investigação mais instigantes e promissores, levando-se em conta os avanços da linguística, os recursos para a experimentação que se sofisticam, as conquistas das neurociências (em certa medida em decorrência do que a pesquisa psicolinguística vem alcançando) e os mistérios que permanecem. A linguagem permeia a atividade humana e é por ela que o ser humano se revela. A pesquisa em linguagem nos aproxima do que há de mais humano em nós.

Entrevista realizada em 06 de junho de 2017. 